\title{
Pyrene-Based Diarynes as Precursors for Twisted Fused Polycyclic Aromatic Hydrocarbons: A Comparison of Two Routes
}

\author{
Sven M. Elbert ${ }^{a}$ \\ Kevin Baumgärtner ${ }^{a}$ \\ Joshua A. Esteves ${ }^{a}$ \\ Laura Weber ${ }^{a}$ \\ Frank Rominger ${ }^{a}$ \\ Michael Mastalerz ${ }^{* a}$
${ }^{a}$ Organisch-Chemisches Institut, Ruprecht-Karls-Universität Heidelberg, Im Neuenheimer Feld 270, 69120 Heidelberg, Germany \\ michael.mastalerz@oci.uni-heidelberg.de
}

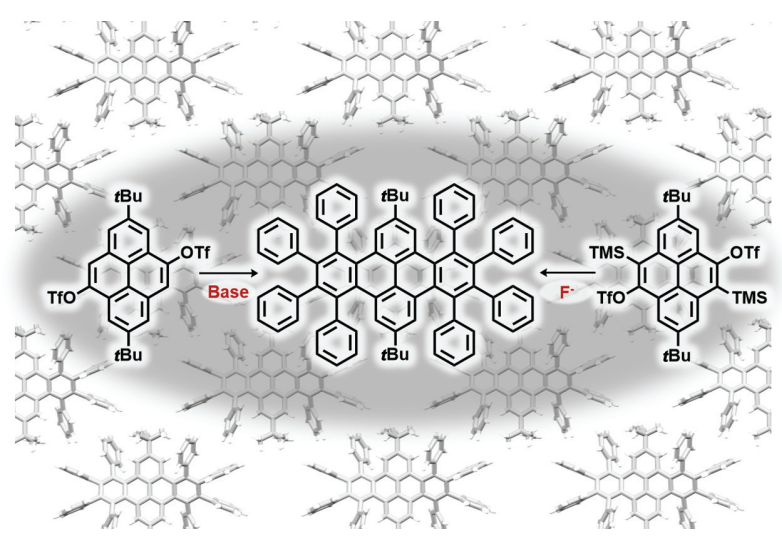

mentioned approach (the [4+2] cycloaddition), pyrene derivatives can either act as precursors for arynes as dienophiles or as dienes. The latter was frequently used for the synthesis of PAHs, for example, dibenzo[e,l]pyrenes (path $\mathrm{A}$ in Scheme 1), ${ }^{7}$ despite the fact that pyrene biscyclopentadienones are not very stable under ambient conditions and therefore difficult to purify and handle., ${ }^{3,5,8}$ To the best of our knowledge, the approach with inverse electronic demand on the pyrene scaffold in the reaction with cyclopentadienones (path B in Scheme 1) has not been reported till date. There are a few examples where the in

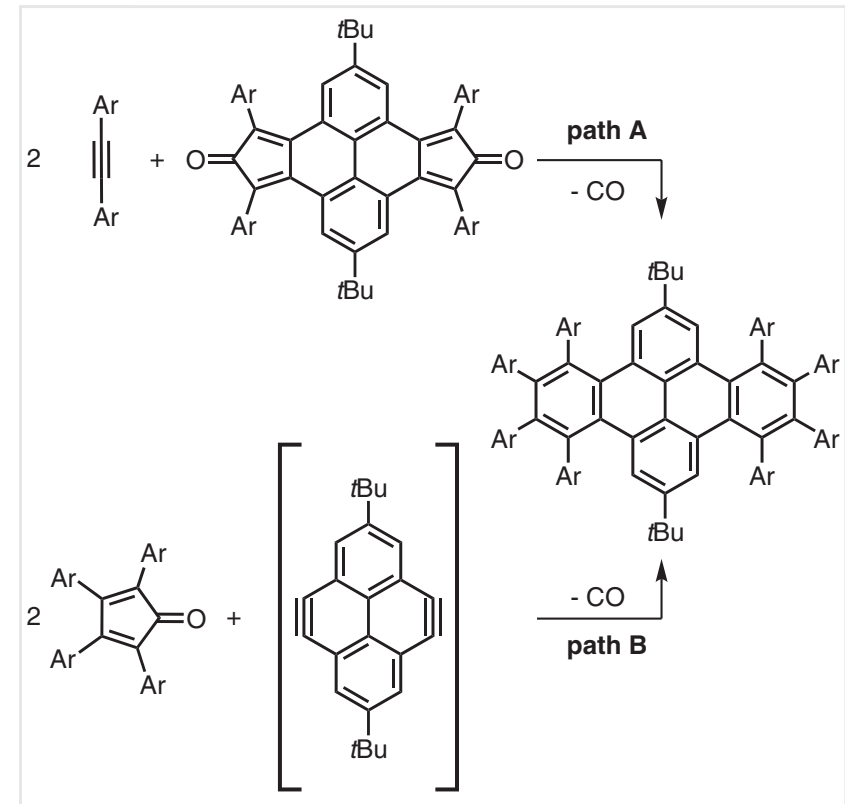

Scheme 1 Comparison of two synthetic approaches involving pyrene biscyclopentadienones (path A) or pyrene diarynes (path B) exemplarily shown for the synthesis of dibenzo[e,l]pyrenes. 
situ generation of pyrene-based bis-arynes has been described in the cycloaddition to furans, ${ }^{9,10}$ benzofurans, ${ }^{11}$ or arylacetonitrils. ${ }^{12}$ In all these cases, either pyrene dibromides $^{9,12}$ or tetrabromides ${ }^{10,11,13}$ have been used as molecular precursors, which were transformed into the arynes with non-nucleophilic bases, or $n$-BuLi. Similar to aryl bromides, aryl triflates ${ }^{14}$ can be transformed into arynes by non-nucleophilic bases, or, more elegant, orthoTMS triflates ${ }^{15}$ as bench stable precursors that are in situ transformed to arynes by fluoride anions.

Here we describe two routes to access pyrene-based diaryne precursors as bench-stable compounds for the synthesis of larger PAHs, such as twistarenes by [4+2] cycloadditions. ${ }^{16,17}$

\section{Results and Discussion}

The synthesis of both aryne precursors $\mathbf{3}$ and $\mathbf{6}$ started from 4,9-diborylated pyrene $\mathbf{1}$, which can be readily synthesized via literature-known procedures on gram scale. ${ }^{18}$ Base-mediated $\left(\mathrm{NaOH}_{\mathrm{aq}}\right)$ oxidation using $\mathrm{H}_{2} \mathrm{O}_{2}$ gave the corresponding pyrene diol $\mathbf{2}$ in $80 \%$ yield after recrystallization from a chloroform $/ n$-heptane mixture (Scheme 2). The condensation with trifluoromethanesulfonic anhydride $\left(\mathrm{Tf}_{2} \mathrm{O} ; 2.4\right.$ equiv) under standard conditions [ $\mathrm{NEt}_{3}$ (4 equiv), $\mathrm{CH}_{2} \mathrm{Cl}_{2}$ ] gave pyrene bistriflate 3 in $68 \%$ yield (Scheme 2). Diol 2 and bistriflate $\mathbf{3}$ have been fully characterized by common analytical methods (see the
Supporting Information, SI). Additionally, the structure of bistriflate 3 was proven by single-crystal X-ray analysis (SCXRD; Scheme 2, top right).

To synthesize bis-TMS triflate $\mathbf{6}$, pyrene diol $\mathbf{2}$ was selectively ortho-brominated using NBS and ${ }^{\mathrm{i}} \mathrm{Pr}_{2} \mathrm{NH}_{2}$ to give dibromo dihydroxy pyrene 4 in $96 \%$ yield. ${ }^{19}$ Using hexamethyldisilazane, 4 was transformed in $84 \%$ yield to the double TMS ether 5 (Scheme 2). Subsequently, 5 was converted under Sila-Fries ${ }^{20}$ conditions (1. nBuLi; 2. $\mathrm{Tf}_{2} \mathrm{O}$ ) under careful control of the reaction temperature $\left(-100{ }^{\circ} \mathrm{C}\right.$ to $-80{ }^{\circ} \mathrm{C}$ ) to the TMS triflate 6 and isolated in $54 \%$ yield. Pyrenes 4, 5, and 6 have been fully characterized (see SI) and the structures of $\mathbf{5}$ (see SI) and $\mathbf{6}$ (Scheme 2, right, bottom) were additionally proven by SCXRD analyses.

The in situ generation of pyrene diarynes from $\mathbf{3}$ and $\mathbf{6}$ was investigated in the Diels-Alder reaction with tetracyclone 7 to obtain PAH 8 (Scheme 3), whose dibenzo[e,l] pyrene core structure was till now only accessible via path $A$ with dodecyl chains as discussed in Scheme 1. ${ }^{7}$ Different bases for the deprotonation of bistriflate $\mathbf{3}$ were tested to generate the aryne in situ and react with tetracyclone $\mathbf{7}$ to give 8. Neither $\mathrm{KO}^{t} \mathrm{Bu}$ in different solvents (THF, $\mathrm{Et}_{2} \mathrm{O}, \mathrm{Ph}_{2} \mathrm{O}$ ) in a wide temperature range $\left(0^{\circ} \mathrm{C}\right.$ to $\left.180^{\circ} \mathrm{C}\right)$ nor $n$-BuLi gave the twisted PAH 8. Treatment of $\mathbf{3}$ with lithium hexamethyldisilazane as a strong non-nucleophilic base for $21 \mathrm{~h}$ at $-78{ }^{\circ} \mathrm{C}$ to $\mathrm{rt}$ followed by thermal treatment at $150{ }^{\circ} \mathrm{C}$ for $3 \mathrm{~h}$ (for details, see SI) resulted in 8, which was isolated in $40 \%$ yield after column chromatography (Scheme 3). Besides characterization by ${ }^{1} \mathrm{H}$ and ${ }^{13} \mathrm{C}$ NMR spectroscopy, a

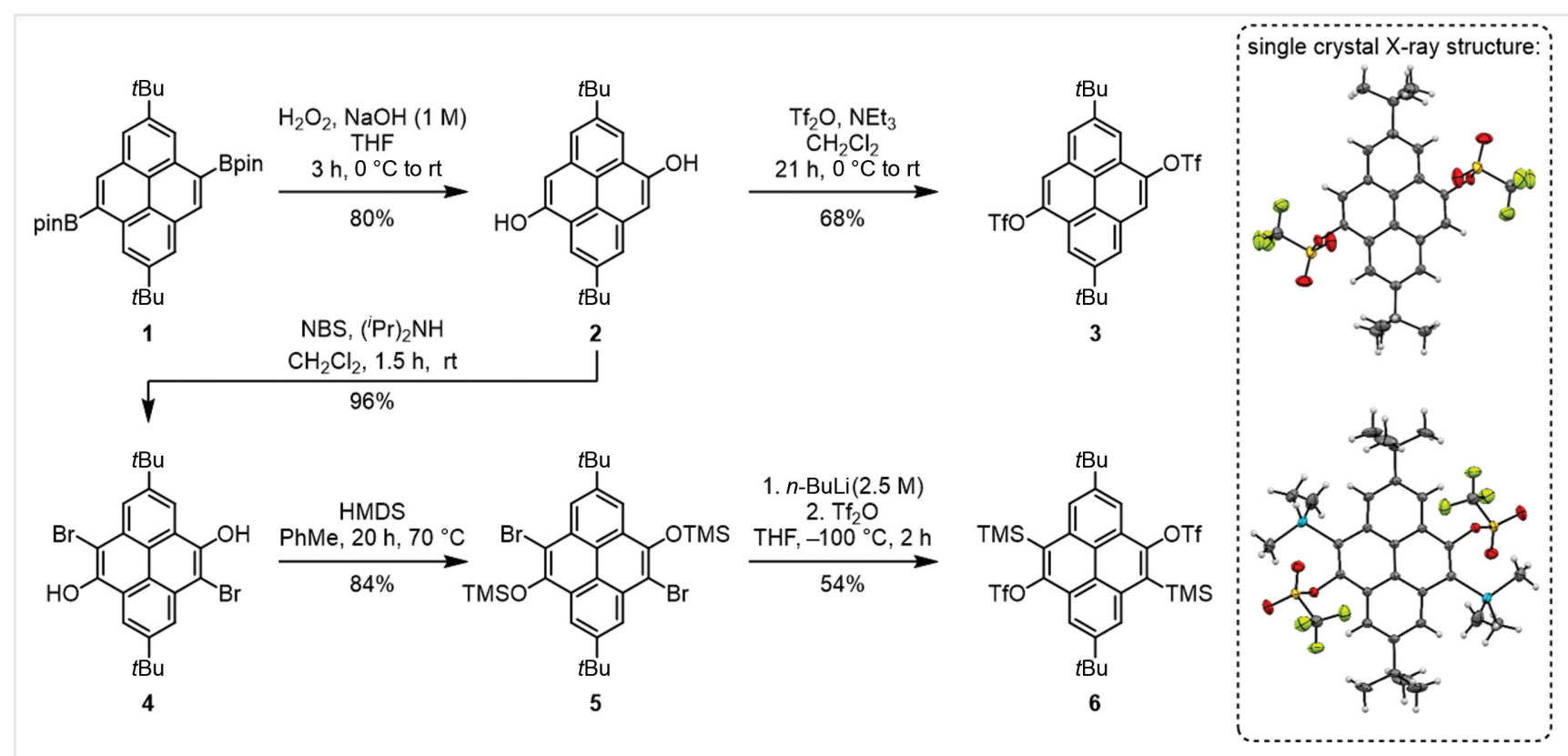

Scheme 2 Left: synthesis of the pyrene-based diaryne precursors $\mathbf{3}$ and $\mathbf{6}$ from bisborylated pyrene $\mathbf{1}$. Right: single-crystal X-ray structures of $\mathbf{3}$ (top) and $\mathbf{6}$ (bottom) as thermal ellipsoids at the 50\% probability level. Carbon: grey; hydrogen: white; oxygen: red; sulfur: yellow; fluorine: lime, silicon: light blue. HMDS: hexamethyldisilazane. 
<smiles></smiles><smiles>O=C(C(=C1C2CC3CC(C2)CC1C3)c1ccccc1)c1ccccc1</smiles>

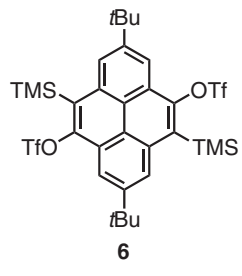

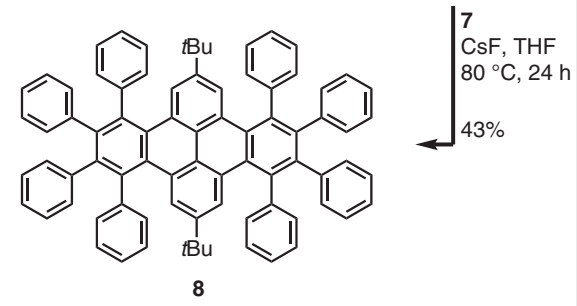

8

Scheme 3 Synthesis of PAH 8 by the Diels-Alder reaction of aryne precursors $\mathbf{3}$ and $\mathbf{6}$, respectively with tetracyclone $\mathbf{7}$.

molecular ion peak at $m / z=1022.575$ (calcd. for $\mathrm{C}_{80} \mathrm{H}_{62}$ : 1022.485 ) for $[\mathbf{8}]^{+}$was clearly detected by MALDI-TOF MS (see SI). As mentioned above, TMS triflate $\mathbf{6}$ was also used as an aryne precursor, which was generated by CsF in THF at 80 ${ }^{\circ} \mathrm{C}$ to give nearly the same yield of $\mathbf{8}(43 \%)$, again after thermal treatment.

By slow evaporation of an $n$-hexane $/ \mathrm{CHCl}_{3}$ solution of 8, crystals of suitable quality for single-crystal X-ray diffraction have been obtained (Figure 1).

PAH 8 crystallizes in the orthorhombic space group Fddd with $Z=8$ and approximately 24 molecules of disordered chloroform within the one-dimensional channels along the $a b$-plane formed by PAH 8 , which had to be removed by the SQUEEZE routine function of Platon. ${ }^{21}$ Because of the eight phenyl groups of the aromatic backbone of $\mathbf{8}$, the dibenzo[e, l]pyrene core structure is contorted by $49.6^{\circ}$ (considering the outer edges, see Figure 1 b, c), creating a helical chirality. This twist is noticeably smaller than that for the structurally related dodecaphenyltetracene $\left(97^{\circ}\right)^{17}$ due to the stiffening of the tetracene backbone by the annulated benzene rings. Within the racemic crystal structure of $\mathbf{8}$, enantiopure sheets can be found (Figure 1d) with dispersion interactions between the peripheral phenyl group and the tert-butyl groups as main interactions (Figure 1e). Dibenzo[e,l]pyrene 8 was furthermore investigated using UV-vis spectroscopy and the colorless compound shows an absorption maximum at $\lambda_{\mathrm{abs}}=309 \mathrm{~nm}(\log \varepsilon=4.71)$. Upon excitation $\left(\lambda_{\mathrm{ex}}=309\right.$ $\mathrm{nm})$, a blue fluorescence with $\lambda_{\mathrm{em}}=412 \mathrm{~nm}$ and a resulting considerably large Stokes shift of $\tilde{V}=8090 \mathrm{~cm}^{-1}$ were observed (see SI).

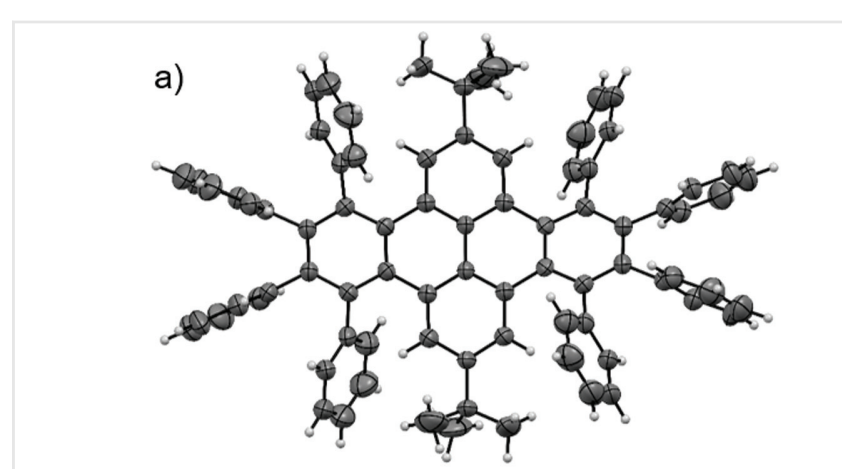

d)

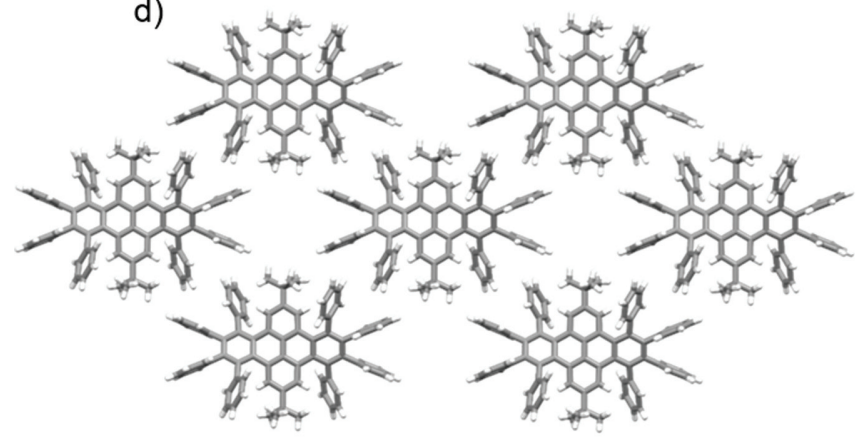

b)

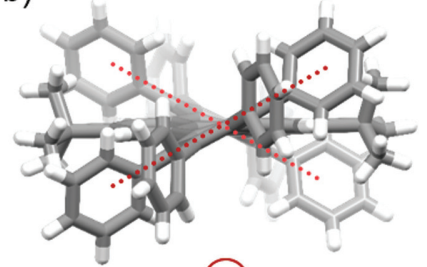

(M)

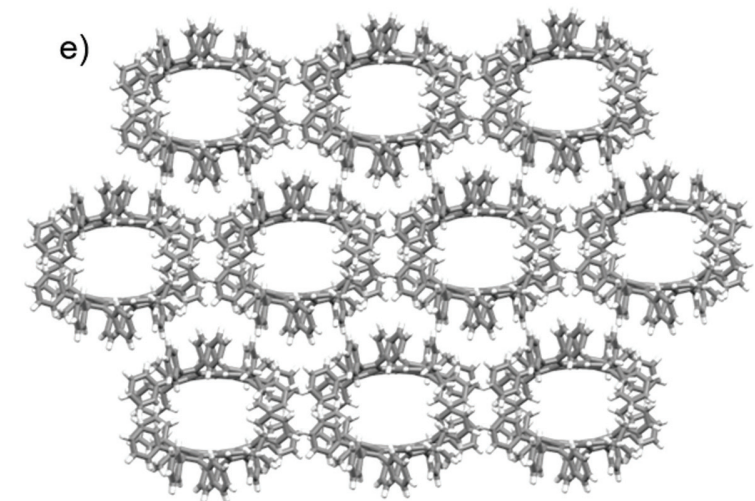

Figure 1 Single-crystal X-ray structure of dibenzo[e,l]pyrene 8. a) Thermal ellipsoid plot shown at a probability level of $50 \%$ (only the $M$-enantiomer is shown exemplarily). b) Side view of the helical $M$-enantiomer. c) Side view of the helical $P$-enantiomer. d) Cutout from an enantiopure layer ( $P$ enantiomer) found in the crystal packing. e) View along the $a b$-plane of the crystal packing. Structures b) to e) are depicted as stick models. Carbon: grey; hydrogen: white. 


\section{Conclusions}

Two routes to twisted PAH 8 via different pyrene-based aryne precursors were compared. While for the bistriflate $\mathbf{3}$ low temperatures and a strong non-nucleophilic base (LHDMS) were necessary to generate the desired diaryne, the bis-TMS triflate 6 was transferred to the bis-aryne using $\mathrm{CsF}$ as a fluoride ion source at $80^{\circ} \mathrm{C}$. In both cases, the DielsAlder reaction with tetracyclone gave twisted phenylsubstituted dibenzo[e,l]pyrene $\mathbf{8}$ in comparable yields of $40 \%$ and $43 \%$. Since bistriflate 3 is synthesized with two steps less than $\mathbf{6}$, this route is preferred to generate a valuable pyrene-based aryne in situ. Currently we are exploiting both precursors in the broader sense for PAH synthesis.

\section{Funding Information}

The authors are grateful to the "Deutsche Forschungsgemeinschaft" for supporting this project within the collaborative research center: SFB1249 "N-heteropolycyclic compounds as functional materials" (TP-A04).

\section{Supporting Information}

Supporting information for this article is available online at https://doi.org/10.1055/s-0040-1721851.

\section{References and Notes}

(1) (a) Wu, D.; Ge, H.; Liu, S. H.; Yin, J. RSC Adv. 2013, 3, 22727. (b) Narita, A.; Wang, X.-Y.; Feng, X.; Müllen, K. Chem. Soc. Rev. 2015, 44, 6616. (c) Majewski, M. A.; Stępień, M. Angew. Chem. Int. Ed. 2019, 58, 86. (d) Rüdiger, E. C.; Müller, M.; Freudenberg, J.; Bunz, U. H. F. Org. Mater. 2019, 01, 001.

(2) (a)Simpson, C.D.; Mattersteig, G.; Martin, K.; Gherghel, L.; Bauer, R. E.; Räder, H. J.; Müllen, K. J. Am. Chem. Soc. 2004, 126, 3139. (b) Smyth, N.; Van Engen, D.; Pascal, R. A.J. Org. Chem. 1990, 55, 1937.

(3) Chen, W.; Li, X.; Long, G.; Li, Y.; Ganguly, R.; Zhang, M.; Aratani, N.; Yamada, H.; Liu, M.; Zhang, Q. Angew. Chem. Int. Ed. 2018,57, 13555.

(4) Dötz, F.; Brand, J. D.; Ito, S.; Gherghel, L.; Müllen, K. J. Am. Chem. Soc. 2000, 122, 7707.

(5) (a) Byun, Y.; Coskun, A. Chem. Mater. 2015, 27, 2576. (b) Byun, Y.; Cho, M.; Kim, D.; Jung, Y.; Coskun, A. Macromolecules 2017, 50, 523.

(6) (a) Wang, L.; Han, Y.; Zhang, J.; Li, X.; Liu, X.; Xiao, J. Org. Lett. 2020, 22, 261. (b) Baumgärtner, K.; Rominger, F.; Mastalerz, M. Eur.J. Org. Chem. 2019, 4891. (c) Baumgärtner, K.; Meza Chincha, A. L.; Dreuw, A.; Rominger, F.; Mastalerz, M. Angew. Chem. Int. Ed. 2016, 55, 15594.
(7) Wasserfallen, D.; Kastler, M.; Pisula, W.; Hofer, W. A.; Fogel, Y.; Wang, Z.; Müllen, K. J. Am. Chem. Soc. 2006, 128, 1334.

(8) Baumgärtner, K.; Kirschbaum, T.; Krutzek, F.; Dreuw, A.; Rominger, F.; Mastalerz, M. Chem. Eur. J. 2017, 23, 17817.

(9) Moursounidis, J.; Wege, D. Aust. J. Chem. 1988, 41, 235.

(10) (a) Itami, K.; Segawa, Y.; Watanabe, K.; Cheung, K. Y.; Watanabe, K.; Segawa, Y.; Itami, K. ChemRxiv 2020, preprint; https://doi. org/10.26434/chemrxiv.12324353.v2. (b) Franz, D.; Robbins, S. J.; Boeré, R. T.; Dibble, P. W. J. Org. Chem. 2009, 74, 7544.

(11) Wang, J.; Miao, Q. Org. Lett. 2019, 21, 10120.

(12) Han, W.; Tran, J.; Zhang, H.; Jeffrey, S.; Swartling, D.; Ford, G. P.; Biehl, E. Synthesis 1995, 827.

(13) Han, Y.; Dong, S.; Shao, J.; Fan, W.; Chi, C. Angew. Chem. Int. Ed. 2020. Doi: 10.1002 /anie.202012651.

(14) (a) Wickham, P. P.; Hazen, K. H.; Guo, H.; Jones, G.; Reuter, K. H.; Scott, W. J. J. Org. Chem. 1991, 56, 2045. (b) Truong, T.; Mesgar, M.; Le, K. K. A.; Daugulis, O. J. Am. Soc. Chem. 2014, 136, 8568. (c) Reuter, K. H.; Scott, W. J. J. Org. Chem. 1993, 58, 4722. (d) Pun, S. H.; Wang, Y.; Chu, M.; Chan, C. K.; Li, Y.; Liu, Z.; Miao, Q. J. Am. Chem. Soc. 2019, 141, 9680. (e) Mesgar, M.; Nguyen-Le, J.; Daugulis, O. Chem. Commun. 2019, 55, 9467.

(15) Pérez, D.; Peña, D.; Guitián, E. Eur. J. Org. Chem. 2013, 5981.

(16) (a) Pascal, R. A. Jr Chem. Rev. 2006, 106, 4809. (b) Xiao, J.; Liu, S.; Liu, Y.; Ji, L.; Liu, X.; Zhang, H.; Sun, X.; Zhang, Q. Chem. Asian J. 2012, 7, 561. (c) Xiao, J.; Duong, H. M.; Liu, Y.; Shi, W.; Ji, L.; Li, G.; Li, S.; Liu, X.-W.; Ma, J.; Wudl, F.; Zhang, Q. Angew. Chem. Int. Ed. 2012, 51, 6094. (d) Xiao, J.; Divayana, Y.; Zhang, Q.; Doung, H. M.; Zhang, H.; Boey, F.; Sun, X. W.; Wudl, F. J. Mater. Chem. 2010, 20, 8167. (e) Walters, R. S.; Kraml, C. M.; Byrne, N.; Ho, D. M.; Qin, Q.; Coughlin, F. J.; Bernhard, S.; Pascal, R. A. Jr J. Am. Chem. Soc. 2008, 130, 16435. (f) Qiao, X.; Padula, M. A.; Ho, D. M.; Vogelaar, N. J.; Schutt, C. E.; Pascal, R. A. J. Am. Chem. Soc. 1996, 118, 741. (g) Qiao, X.; Ho, D. M.; Pascal, R. A. Jr Angew. Chem. Int. Ed. Engl. 1997, 36, 1531. (h) Lu, J.; Ho, D. M.; Vogelaar, N. J.; Kraml, C. M.; Bernhard, S.; Byrne, N.; Kim, L. R.; Pascal, R. A. Jr J. Am. Chem. Soc. 2006, 128, 17043. (i) Duong, H. M.; Bendikov, M.; Steiger, D.; Zhang, Q.; Sonmez, G.; Yamada, J.; Wudl, F. Org. Lett. 2003, 5, 4433. (j) Clevenger, R. G.; Kumar, B.; Menuey, E. M.; Kilway, K. V. Chem. Eur. J. 2018, 24, 3113.

(17) Xiao, Y.; Mague, J. T.; Schmehl, R. H.; Haque, F. M.; Pascal, R. A. Jr Angew. Chem. Int. Ed. 2019, 58, 2831.

(18) Ji, L.; Krummenacher, I.; Friedrich, A.; Lorbach, A.; Haehnel, M.; Edkins, K.; Braunschweig, H.; Marder, T. B.J. Org. Chem. 2018, 83, 3599.

(19) Compound 4 can be isolated in 96\% yield in sufficient purity to be used in further synthetic steps. To obtain an analytical pure sample, purification by column chromatography has to be taken into account, accompanied by a material loss and an isolated yield of $31 \%$ (see the SI).

(20) Korb, M.; Lang, H. Chem. Soc. Rev. 2019, 48, 2829.

(21) (a) van der Sluis, P.; Spek, A. L. Acta Crystallogr., Sect. A: Found. Crystallogr. 1990, 46, 194. (b) Spek, A. Acta Crystallogr., Sect. D: Biol. Crystallogr. 2009, 65, 148. 